\title{
Green growth in oil producing African countries: A panel data analysis of renewable energy demand
}

\author{
Ishmael Ackah and Renatas Kizys*
}

\begin{abstract}
University of Portsmouth, Portsmouth Business School, Subject Group of Economics and Finance, Richmond Building, Portland Street, Portsmouth, Hampshire PO1 3DE, United Kingdom.

E-mail addresses: ishmael.ackah@myport.ac.uk, ackish85@yahoo.com (Ishmael Ackah); renatas.kizys@port.ac.uk (Renatas Kizys) (* corresponding author)
\end{abstract}

\begin{abstract}
Renewable energy has been considered as the solution to the hydra-headed problems of energy security, energy access and climate change, especially in Africa. In addition, renewable energy sources, such as the sun, wind, wave and waste abound in Africa in need of investment. In order to provide both policy and investment guide, this study investigates the drivers of renewable energy demand in oil-producing African countries. Three panel data models - a random effect model, a fixed effects model and a dynamic panel data model - are used to estimate renewable energy demand with a comprehensive set of determinants. The estimation results indicate that the main drivers of renewable energy in oil-producing African countries are real income per capita, energy resource depletion per capita, carbon emissions per capita and energy prices. The study recommends that policies should encourage the consumption of commercial sources of renewable energy to attract the needed investments.
\end{abstract}

JEL: Q2, Q4, Q21

Keywords: Renewable energy demand, energy access, panel data analysis, economic growth

Acknowledgements: We would like to thank the editor and two anonymous reviewers for their constructive comments, which have helped to considerably improve our paper. The usual disclaimer applies. 


\subsection{Introduction}

Economic growth has long been considered a solution to unemployment, poverty and equity issues (Boqiang, 2003) making growth the ultimate goal of every economy. This is because economic growth enhances the standard of living and aids the development of human capital. It has further been established that energy is a key a determinant of economic growth (Stern and Cleveland, 2004). According to Stern and Cleveland (2004), energy is the pivot on which the wheels of society turn. Energy facilitates heating, lighting, transport, and the transformation of inputs into outputs. Thus, energy is a key factor for economic development. This means that energy challenges such as the oil price crises in 1973 and 1979 and 2008, climate change and potential depletion of fossil energy sources, present an opportunity to the World to reflect and consider energy issues since they could be a limiting factor to economic growth.

Coupled with these factors, energy access has been a critical challenge to economic development in Africa. Access to modern form of energy is necessary, and a requirement for development since energy has been found to be a key factor of production. However, in sub-Saharan Africa (SSA), just $31 \%$ of the population access to modern energy, such as (IEA, 2010). Out of about 1.4 billion people without access to energy globally, $15 \%$ are in SSA. Out of the 587 million people without access to electricity in Africa, 585 million are in SSA. Can one imagine London or New York without electricity for one hour? That will be disaster! Many businesses will come to halt and many will become inefficient without energy. This makes the use of energy indispensable. These statistics therefore threaten sustainable development, may hinder development and prevent many countries from achieving the Millennium Development Goals. The World Bank (2001) finds a strong correlation between electricity access and reduction in poverty. The study also indicates that efficiency and clean energy is crucial to the reduction of 
poverty and essential for economic growth, particularly in rural areas. For instance, business activities, including opening of cold store to sell fish, selling chilled water and drinks, night-time sewing and hair dressing can be undertaken in rural areas when there is access to electricity. These activities increase employment, income and overall development of the area.

This notwithstanding, energy use has negative environmental consequences. The World Resource Institute estimates that $61.4 \%$ of global greenhouse emissions emanate from energy consumption. Thus, any solution that reduces the negative effect of energy consumption should include investment in cleaner and reliable sources of energy to allow energy to play its role in the economy without endangering the environment. Hence, two key forms of energy - energy efficiency and renewable energy consumption - stand out.

Renewable energy such as wind, solar, geothermal, wave and waste have the advantage of being carbon-neutral and non-depletable (Sadorsky, 2011). Renewable energy therefore becomes the solution to the recent concerns of energy security, sustainable development and climate change for three reasons. First, renewable energy sources abound in Africa and can continually supply energy over a long term if developed. Second, renewable energy can aid the provision of modern energy to rural areas and other places that are difficult to be reached by the electricity grid. Third, renewable energy can help to offset the proportion of foreign exchange that is used to import oil. In order to enhance sustainable energy supply, there is the need to invest in renewables whilst curbing the use of fossil fuel. This calls for a forced choice between fossil fuel and renewable energy. However, this choice can have environmental, investment and growth consequences.

Global investment in new renewable capacity increased to USD 120 billion in 2008 (REN21 2009). Annual percentage gains for 2008 also show significant achievements in all types of 
renewable energy, especially the grid connected solar photovoltaic capacity, which grew by $70 \%$. In addition, wind power grew by $29 \%$, solar hot water increased by $15 \%$, and small hydro expanded by $8 \%$ (El-Ashry, 2009). Notably, such investments usually take place in developed economies, such as the European Union. By contrast, the major forms of renewable energy consumption in Africa are biofuels and waste (IEA, 2010). These traditional and typically unprocessed renewable forms of energy consumption comprise wood fuel, charcoal, animal waste and agricultural residues (Karekezi, 2002). They trigger both health and environmental effects, such as respiratory diseases, degradation and deforestation (Kantai, 2002). There is the need to harness the modern forms of renewable energy to curb these problems. According to Deichmann et al. (2011), Africa has a renewable energy potential in the form of abundant sunshine all year round for solar energy, river and water bodies for hydroelectric dams and wind energy potential. Karekezi et al. (2003) find that only $7 \%$ of Africa's hydro potential is harnessed. Since renewable energy investments require huge capital outlay, the drivers of renewable energy need to be examined to guide policy design.

Africa features 1.1 Gigawatts hydropower capacity, 900 Megawatts of geothermal potential, abundance wind and solar potential (Karekezi and Ranja, 1997). To transform these potential energy resources into energy supply, there is a need for both private and public investment in the sector. This calls for studies that aid renewable energy policy designs and help to make investment decisions in the sector. Unfortunately, few studies have been conducted on renewable energy in Africa. For instance, Bugaje (2006) reviews renewable energy policies of Egypt, Mali, Nigeria and South Africa and finds that (i) the use of fuel wood can create environmental damages, and (ii) Africa has the potential of harnessing the renewable energy potential given the 
right investment and human capital. Karekezi and Kithyoma (2002) suggest that for Africa to harness its renewable energy potential there is the need for long term planning and financing. This study contributes to the literature on energy in four main ways: First, we attempt to fill both the literature and policy gap by investigating the impact of energy resource depletion on renewable energy consumption in oil-producing African countries. The inclusion of energy resource depletion allows assessing whether the potential depletion of fossil fuels has effect on the amount of renewable energy consumed. Second, the effect of energy-related carbon emissions on renewable energy demand is evaluated. That is, since carbon emissions in Africa can be attributed to several factors such as bush burning, farming activities and energy consumption, it is prudent to distinguish the effect of energy related emissions on renewable energy consumption. Third, by means of a dynamic panel data model, the effects of past values of renewable energy demand on current consumption are assessed. The study further employs a one-way random effects and fixed effects models with instrumental variables. Fourth, a distinctive feature of the study consists of using a comprehensive set of determinants of renewable energy demand.

This paper is organized as follows. Section 2 provides a review of the existing literature on the determinants of renewable energy demand and looks at the relation between renewable energy and sustainable development in Africa. Section 3 summarizes the data and outlines the methodology. Section 4 presents and analyzes research findings. Section 5 concludes and provides policy recommendations.

\subsection{Literature Review}


The need to control the environmental effects of energy consumption and enhance energy security has led to the design of renewable energy policies. An example is the 20-20-20 policy of the European Union, which seeks (i) to reduce greenhouse emissions by $20 \%$ (relative to the 1990 level), (ii) $20 \%$ improvement in energy efficiency and (iii) increase the share of renewable energy in the energy mix to $20 \%$ by 2020 . Due to such policies, there has been a gradual increase in studies on the factors that influence renewable energy in Europe in particular and in the developed countries in general. The data envelope analysis is applied to 45 economies by Chien and $\mathrm{Hu}(2008)$ to analyze the effects of renewable energy on the technical efficiency of 45 economies over the period 2001-2002. They find that an increase in the use of renewable energy improves an economy's technical efficiency while an increase in the use of traditional energy (fossil fuel) decreases technical efficiency.

Sadorsky (2009a) studies renewable energy consumption for the emerging countries in a panel cointegration. He shows that in the long run, increases in real GDP per capita and CO2 per capita are found to be major drivers behind per capita renewable energy consumption. Oil price increases have a smaller albeit negative impact on renewable energy consumption. Specifically, in the long run, a $1 \%$ increase in real income per capita increases consumption of renewable energy per capita in emerging economies by approximately 3.5\%. Long-run renewable energy per capita consumption price elasticity estimates are approximately equal to -0.70 . These results are robust across two different panel cointegration estimators.

Sadorsky (2009b) employs a panel-cointegrated FMOLS model to investigate the relation between renewable energy consumption and economic growth in G7 countries. He shows that a $1 \%$ increase in real GDP per person increases per capita renewable energy consumption by 
$8.44 \%$, while a $1 \%$ increase in carbon dioxide emissions per person increases per capita renewable energy consumption by $5.23 \%$.

Bowden and Payne (2010) study the causality between residential consumption of renewable energy and economic growth in the US from 1946 to 2006 and find a unidirectional causal relation from residential renewable energy consumption to growth. Apergis and Payne (2010) find bidirectional causality in both the short and long-run between renewable energy consumption and economic growth.

Marques et al. (2010) use panel regression techniques to investigate the relationship between renewable energy consumption, political factors, socioeconomic factors, and country specific factors for a panel of 24 European counties covering the period 1990-2006. They find that lobby efforts from the fossil fuel sector, and $\mathrm{CO} 2$ emissions reduce renewable energy consumption, while reducing energy self-sufficiency promotes renewable energy consumption. Menyah and Wolde-Rufael (2010) use vector auto-regression techniques to study the relationship between carbon dioxide emissions, renewable energy consumption, nuclear consumption and real GDP for the US over the period 1960-2007. They find causality running from nuclear energy consumption to $\mathrm{CO} 2$ emissions but no causality running from renewable energy consumption to $\mathrm{CO} 2$ emissions. There is evidence of causality running from GDP to renewable energy. Apergis and Payne (2011) use panel cointegration techniques to examine the relationship between renewable energy consumption and economic growth for a panel of 6 Central American countries over the period 1980-2006. Results from a panel error correction model indicate bidirectional causality between renewable energy consumption and economic growth in both the short- and long-run. 
The literature review reveals two major trends. First, most of the studies on renewable energy concentrate on Europe, Asia, America or developed and emerging countries. In addition, most of these studies test the causal relation between renewable energy and economic growth in a multivariate framework. Studies on renewable energy are important because of the growing concerns over energy security and global warming (Sadorsky, 2009a). According to the IEA (2006), renewable energy is projected to be the fastest growing energy source between 2010 and 2030. Again, though renewable energy consumption-economic growth causality has been extensively investigated, factors that influence renewable energy demand has received less attention especially in the context of Africa. This study contributes to the renewable energy demand literature by studying these factors. Since there is lack of econometric study on renewable energy demand in Africa, this study seeks to fill this gap.

\subsection{Renewable Energy and Sustainable Growth in Africa}

Africa has been growing in terms of population and development over the last two decades. According to the International Renewable Energy Agency (IRENA, 2012), Africa's population will be 2 billion by 2050 with 40\% living in rural areas. The accelerated population growth will put pressure on energy resources. The IEA (2012) estimates that in 57\% of Africa's population had no access to electricity in 2010. This implies that there is the need to provide modern energy to the present generation and make plans to cater for the future ones. Apart from population, economic growth has also been a vital reason for African economies to develop energy infrastructure. IRENA (2012) posits that 7 out the 10 fastest-growing economies in the world over the last decade are in Africa and projects Africa's growth to seven-fold by 2050. In order to 
provide sustainable energy that meets both growing population and economy, there is the need to invest in renewable energy.

To begin with, renewable energy sources are indigenous and help to promote self-sufficiency in energy supply. This helps to reduce the impact of price and supply vitality of fossil fuel on the economy. The dependence on renewable energy helps African economies to save the money that would be used to import crude oil. For instance, African economies spent USD 18 billion in 2010 to import crude oil (IRENA, 2012). This amount exceeds the foreign income Africa received in the same period. Adding the cost of oil imports to that of oil subsidies, Africa stands to gain more if there is investment in renewable energy to reduce dependence on oil.

Secondly, renewable energy offers technologically viable alternative to connect rural areas to electricity in the form of off grid or mini grid systems. This will help businesses in remote areas and improve healthcare and education. Thirdly, because renewable energy sources are locally based, they help create jobs in terms of construction, operations and maintenance for the indigenes and the economy as a whole. These advantages together with the fact that renewable energy is carbon-neutral and non-depletable make it the ideal source of energy for sustainable growth in Africa. Since agriculture in Africa is mostly rain-fed, curbing the impact of energy on the climate will help boost productivity.

Karekezi (2002) identifies three main reasons for the growth in renewable energy in Africa. The first reason is the petroleum price increases especially between 1998 and 2011, which induced an increase in import expenditure of African countries. The second reason is the quest of many countries to boost electricity supply and reduce power outages. For instance, countries such as Ghana and Nigeria embarked on power rationing in the past, which had adverse effects on their economic performance. The third reason is the commitment of international bodies to curb global 
emissions. Though efforts have been made to switch from traditional sources of renewable energy to modern sources, the challenge has been the huge upfront investment required for such energy transition. Due to the huge investments required, estimates of the factors that influence renewable energy demand can serve as a guide to predict potential demand and returns on investment.

\subsection{The Methodology}

In Section 3.1, we present and summarize our data set. In Section 3.2, we outline the model that is used to estimate renewable energy consumption.

\subsection{Data}

Annual data from 1985 to 2010 on renewable energy in metric tonnes of oil equivalent is obtained from the International Energy Agency. The renewable energy data captures the sum of hydro, geothermal, wind, solar, industrial waste, municipal waste, biomass, biofuels and charcoal measured in $\mathrm{kg}$ of oil equivalent. GDP in current US dollars serves a proxy for accumulated economic growth. Consumer price index (CPI) represents changes in energy prices. Both GDP and CPI are obtained from the World Bank Development indicators. The choice for consumer price index as a proxy for the energy price variable was informed by two reasons. First, there is unavailability of consistent data on energy prices on the countries under consideration. Second, studies, such as Mahadevan and Asafu-Adjaye (2007) and Tang et al .(2013), use consumer price index as a proxy for energy price when they carried out similar studies on Africa. Our sample includes 12 countries (Algeria, Angola, Cameroon, Congo, Democratic Republic of Congo, Côte d'Ivoire, Egypt, Gabon, Ghana, Nigeria, South Africa, Sudan and Tunisia). Data on human 
capital are unavailable for Gabon. Therefore, Gabon has been excluded from the sample of country-years used to estimate our panel data models. Time series plots of renewable energy demand are provided in Figure 1.

- Please insert Figure 1.0 about here. -

Figure 1.0 indicates that renewable energy consumption per capita underwent significant changes over time. Interestingly, in 6 countries out of 12, renewable energy consumption shows a positive trend, whereas for the remaining countries this trend is negative.

Since renewable energy in Africa is mainly used for cooking or residential purposes and power generation, the study further uses data on carbon emissions that are generated as a result of electricity production. According to Bhattacharya et al. (2014), global warming is highly associated with emissions from energy consumption and production. Moreover, as developing countries move from agrarian to manufacturing economies, they produce more energy and hence emit more carbon. This requires the effect of energy-related carbon emissions to be estimated separately.

- Please insert Table 1.0 about here. -

Table 1.0 summarizes descriptive statistics of the variables used in our study. All variables are expressed in real per capita terms. Gross domestic product per capita (Y), capital per capita (K), human capital per capita (H), and energy depletion (D) per capita are expressed in real 2005 US Dollars (USD). Renewable energy consumption (REN) is measured in $\mathrm{kg}$ per capita of oil 
equivalent. Labor (L) is approximated by a country's population (in millions of persons). CO2 emissions (C) are expressed in tonnes per capita.

Over the sample period and across countries, the mean of real GDP is 2,275.90 real USD per capita. Real GDP per capita varies between 104 and 15,597.28 USD per capita. The degree of variability is also witnessed by the standard deviation. Real GDP deviates from its mean on average by $2,235.85$ USD per capita. The data for this variable are positively skewed (with the value of the skewness standing at 2.2781) and leptokurtic (with the value of kurtosis of 9.6855). The latter suggests that the distribution of real GDP across countries and over time features heavy tails, whereas the former suggests that positive deviations from the mean tend to be more dispersed than negative deviations. Overall, positive skewness and kurtosis collectively result in a non-normal distribution, as indicated by the Jarque-Bera test statistic and the associated probability value.

Real capital per capita is measured as a flow variable. It takes on value 618.18 USD on average across countries and over time. Real capital varies dramatically in the sample of country-years, ranging from the value as low as 4.34 USD to as high as $11,463.16$ USD per capita. Capital also deviates from the mean on average by 949.69 USD per capita, as indicated by the standard deviation. Large positive skewness (5.3973) and large kurtosis (48.2372) lead to the rejection of normality in real capital per capita.

Oil-producing African countries are populated on average by 27.028 million of inhabitants over the sample period. However, this number varies between 0.601 million and 168.834 million with the standard deviation of 29.311 million. Again, the data are positively skewed (with the value of skewness standing at 2.1637) and highly leptokurtic (with the value of kurtosis estimated at 
8.4489). Overall, the null of normality of the data is decisively rejected by the Jarque-Bera test statistic.

Human capital averages 72.78 USD per capita across countries and over time. The data also feature a considerable degree of volatility, as reflected within the range of 1.13 USD and 362.03 USD per capita, and the standard deviation of 71.09 USD per capita. As in the case of real GDP per capita, real capital per capita and population, the data are also positively skewed, with the value of skewness of 1.4284 , and leptokurtic, with the value of kurtosis estimated at 4.6259. Positive skewness and kurtosis jointly result in the non-normality of the data, as witnessed by the Jarque-Bera test statistic and its associated probability.

Energy depletion averages 340.83 USD across countries and over time. Again, the data are highly volatile, with the values ranging from 0 to 7,214.05 USD per capita and the ensuing standard deviation estimated at 747.90 USD per capita. Moreover, energy depletion is positively skewed (with the asymmetry coefficient standing at 4.4662) and highly leptokurtic (the value of kurtosis of 28.9407). Overall, the null of normality is decisively rejected by the Jarque-Bera test statistic.

CO2 emissions per capita are estimated at 0.4991 tonnes per capita across countries and over time. The data vary between 0.0014 and 5.1213 tonnes per capita. The range of variation causes the data to deviate from the sample mean by 1.0449 tonnes per capita. Again, we observe positive skewness (with the asymmetry coefficient standing at 2.9529) and large kurtosis (with the value of kurtosis standing at 10.5158). Subsequently, the Jarque-Bera test statistic provides strong evidence of non-normality in the data. 
The price level averages 55.4985 across countries and over time. The price level deviates from its mean by on average 52.3942 . The price level is relatively less skewed than the other variables in our study. More specifically, the coefficient of skewness is 0.8933. Likewise, kurtosis (3.5515) is also lower relative to the other variables. Nevertheless, positive skewness and kurtosis cause a significant departure from normality in the data, as the probability associated to the Jarque-Beta test statistic is close to zero.

Lastly, renewable energy consumption averages $249.8569 \mathrm{~kg}$ of oil equivalent per capita. The values range from 0.397184 and $822.7332 \mathrm{~kg}$ per capita, with the standard deviation estimated at $204.922 \mathrm{~kg}$ per capita. It is positively skewed (1.2530) and leptokurtic (4.1765). Therefore, the Jarque-Bera test statistic unambiguously rejects the null of normality in the data.

- Please insert Table 2.0 about here. -

Table 2.0 reports the Pearson coefficients of unconditional correlation among the variables under investigation. Key to the correlation analysis is the unconditional correlation between the dependent variable (renewable energy consumption) and the explanatory variables. Renewable energy consumption is positively correlated with GDP per capita (0.4198), capital per capita (0.4022) and energy depletion (0.5519). It is negatively correlated with human capital (-0.4110). All other coefficients of correlations of renewable energy consumption are close to zero. GDP per capita shows a large positive correlation with capital per capita (0.8853), human capital (0.9381), and energy depletion (0.7800). Overall, the coefficients of unconditional correlation vary substantially. 
- Please insert Table 3.0 about here. -

Table 3.0 reports results of the integration (unit root) and cointegration tests of the variables under investigation. We employ three panel unit root tests, the Levin, Lin and Chu (LLC), Im, Pesaran and Shin (IPS) and Phillips and Perron (PP) tests. Each unit root test is summarized in two columns. The first column assumes the presence of a constant in the test equation, whereas the second column assumes the presence of both a constant and a linear trend in the test equation. The LLC test assumes a common unit root, whereas the IPS and the PP tests assume individual unit root processes. The null hypothesis assumes the presence of a unit root in the variable. If the null is rejected then the variable is deemed to be stationary. The unit root tests suggest that all variables are non-stationary, since the null of a unit root cannot be rejected. Carbon emissions per capita and, to a lesser extent, energy depletion per capita are an exception. However, in the case of energy depletion, the unit root is rejected only if the IPS test is used and only if the test equation includes a constant. In the case of carbon emissions, the unit root is rejected by the LLC and IPS tests, but only if a constant and a linear trend are included in the test equation. Overall, the unit root tests provide only weak evidence against the null of a unit root. Consequently, all the variables will be deemed to be non-stationary. A further battery of unit root tests we carried on the variables in first differences. The results suggest that the variables in first differences are in general stationary. (The results are not reported but are available upon request.) Thus, the variables in levels are diagnosed to be integrated of order 1. 
We further test whether the variables are cointegration, that is, whether the share a common stochastic trend. To this end, we used the Kao test for cointegration. The null hypothesis of no cointegration is rejected. We thus conclude that the variables share a common stochastic trend. The presence of cointegration implies that in a panel data regression, the variables can enter in leovels, and the test statistics follow conventional probability density functions.

\subsection{The Model}

This study seeks to investigate the potential determinants of renewable energy demand in oilproducing African countries. The renewable energy demand is modelled as a function of an array of explanatory variables

$$
\operatorname{REN}_{i, t}=F\left(Y_{i, t}, K_{i, t}, L_{i, t}, H_{i, t}, D_{i, t}, C_{i, t}, P_{i, t},\right)
$$

where $i=1, \ldots, N$ sub-indexes countries and $t=1, \ldots, T$ index time periods. Equation (1) relates renewable energy demand $\left(R E N_{i, t}\right)$, GDP per capita $\left(Y_{i, t}\right)$, capital stock per capita $\left(K_{i, t}\right)$, labor force $\left(L_{i, t}\right)$, human capital $\left(H_{i, t}\right)$, energy depletion $\left(D_{i, t}\right)$, energy-related carbon emissions $\left(C_{i, t}\right)$ and energy price $\left(P_{i, t}\right)$. The relation between renewable energy consumption and economic growth in China is instrumented with labor force and carbon dioxide emissions (Lin and Moubarak, 2014). Following Chakravorty et al. (1997), we include energy price and aggregate income as potential determinants of renewable energy demand. In addition, we argue that labor force, human capital, energy depletion and energy-related carbon emissions can trigger changes in renewable energy demand. The inclusion of labor force (as measured by the total size of a country's population) can be rationalized in the following ways. First, labor is a key input to energy production (Wei, 2007). Second, increasing labor force in the African economy poses a challenge to sustainable development of energy resources. Third, labor is key production factor 
in the African economy. Education leads to increase in renewable energy demand through innovation (Isoard and Soria, 2001). This enhances energy efficiency and productivity since a relatively smaller quantity of renewable energy performs the same function. Energy (particular of non-renewable forms of energy) depletion stimulates the use of alternative forms of energy. Increases in energy-related carbon emissions lead to a reduction in renewable energy consumption through the presence of greenhouses gases in the atmosphere, increased levels of pollutions and, consequently, lower crop harvests that are transformed into biomass. Further, since there is no established technology in the literature that transforms inputs into renewable energy (see also Usha Rao and Kishore, 2010), the linear demand function we propose adheres to the principle of parsimony.

Equation (1) can now be expressed as a linear relation between renewable energy consumption and the explanatory variables. Equation (2) is obtained by writing the resulting equation in a panel form with both cross-sectional and time-specific effects.

$\operatorname{REN}_{i, t}=\beta_{0}+\beta_{Y} Y_{i, t}+\beta_{K} K_{i, t}+\beta_{L} L_{i, t}+\beta_{H} H_{i, t}+\beta_{H} D_{i, t}+\beta_{C} C_{i, t}+\beta_{P} P_{i, t}+u_{i, t}$

To estimate the renewable energy demand in oil-producing African countries, we estimate a panel-data regression. The use of a panel-data regression in studies of energy demand has been limited (for informative review, see Suganthi and Samuel, 2012). Specifically, we employ three different panel-data specifications; a one-way random effects model, a one-way fixed effects effects model and the Arrellano and Bond (1991) generalized method of moments (GMM) estimator of a dynamic panel-data model. We use instrumental variables that address the problem of endogeneity among the explanatory variables (Omri et al., 2014). Additionally, it avoids estimation bias that is associated with the correlation between the lagged dependent variable and the error term. 


\subsection{Empirical Analysis}

In Section 4.1, we present and analyze the estimation results. In Section 4.2, we summarize several robustness checks.

\subsection{Estimation Results}

We estimate three panel data models, a one-way random effects model, a one-way fixed effects model and a dynamic panel model. The Hausman test finds no evidence against the assumption that the random effects are uncorrelated with the predictors, thus lending support to the random effects model, as opposed to fixed-effects model. ${ }^{1}$ The dynamic panel data model is estimated by using the GMM estimation method, proposed by Arellano and Bond (1991). The use of an instrumental variable approach to estimate our panel data models address the endogeneity issue of some of the predictors, notably real income per capita ${ }^{2}$ (see also Fang, 2011). To this end, the predictors are instrumented with the first lag of the explanatory variables (the second lag of renewable energy consumption in the case of the dynamic panel data model). In specifications 1 to 7 , predictors of renewable energy consumption enter regressions individually, whereas specification 8 employs the entire set of predictors. The estimation results of the one-way fixed effects model and the dynamic panel data model are briefly analyzed in Section 4.2.

- Please insert Table 4.0 about here. -

\footnotetext{
${ }^{1}$ Results of the Hausman test are not reported, but are available from the authors upon request. Nevertheless, we also report the results of the one-way fixed effects model.

${ }^{2}$ We use the test for Granger non-causality in a pooled VAR that involves renewable energy consumption and GDP per capita. The Granger non-causality test suggests that that information about renewable energy consumption does not contribute to the forecasting accuracy of GDP per capita. Results of the Granger non-causality tests are not reported, but are available from the authors upon request.
} 
Table 4.0 reports the estimation results for the one-way random effect model. We first find that GDP per capita has positive and significant effect (at the 5\% significance level) on renewable energy consumption (Table 4.0). Higher economic growth may lead to increased renewable energy consumption in oil producing Africa countries. For instance, the estimation results of specification (1) imply that a one US dollar increase in GDP per capita will lead to an increase in renewable energy demand in $0.00384 \mathrm{~kg}$ of oil equivalent per person. This result is validated by specification (8) that estimates the effects of the explanatory variables collectively. This finding is consistent with Asafu-Adjaye (2000) and Sadorsky (2009) and Shabbaz et al (2013). Since economic growth is vital for renewable energy consumption, it would be policy-prudent to promote the linkage between economic growth and renewable energy consumption. When consumers' income increases or profits of firms rise, they can switch to alternative sources of energy. Key to the aforementioned linkage is energy policy pursued by governments in countries such as Ghana, Nigeria, Algeria and Angola, which aim at increasing the contribution of renewable energy to $10 \%$ in aggregate energy consumption by 2020 . This has led to the introduction of subsidies and economic benefits that encourage the deployment and use of solar and mini-hydro dams.

The estimated effect of capital is significant, albeit not robust in specifications (2) and (8). In the individual effects model, capital exerts a positive and significant influence on renewable energy consumption. The estimated effect of capital in specification (2) indicates that one dollar increase in capital leads to an increase in renewable energy consumption by $0.00914 \mathrm{~kg}$ of oil equivalent per capita. Investment in capital promotes renewable energy consumption. This finding agrees with the theory of underlying energy demand, which argues that energy has an indirect demand and the amount of energy consumed is influenced by the type of capital appliance. However, this 
finding contrasts with the estimated effect of capital in a more general model. When renewable energy demand is regressed against capital and other potential determinants the effect of capital remains significant, but the sign switches from being positive to being negative. This may imply that other factors reduce the impact of capital on renewable energy consumption. Arguably, the lack of stability in the coefficient sign in specification (8) may also be a statistical artefact that is associated with the existence of multicollinearity among the explanatory variables. If this is the case, then the estimated effect of capital in specification (2) indicates that one dollar increase in capital leads to an increase in renewable energy consumption by $0.00914 \mathrm{~kg}$ of oil equivalent per capita. Investment in capital promotes renewable energy consumption.

The use of human capital in our models is based on the notion that more educated people are expected to consume more renewable energy due to the awareness of carbon emissions and environmental consequences of energy consumption. Although in specification (4), the coefficient estimate has the expected positive sign, the effect is not significant.

Further, renewable energy has three principal advantages. It is carbon neutral, available and widely distributed geographically and non-depletable. It is expected the depletion of energy resources will lead to higher renewable energy consumption. Indeed, in an attempt to encourage sustainability, policy makers will encourage renewable energy consumption. The estimated effect of energy depletion lends support to our ex-ante expectation. Specifically, an increase in energy resource depletion in 1 USD per capita is associated with the increase in the renewable energy consumption by $0.00536 \mathrm{~kg}$ of oil equivalent per capita.

The role of carbon emissions for renewable energy consumption is underscored by Lund (2007). (Bhattacharya et al., 2014) find that renewable energy is carbon-neutral due to its potential to 
mitigate the presence of greenhouse gases in the atmosphere. However, the possibility of causal effects running from carbon emissions to renewable energy demand has been ignored the related literature. In this regard, the coefficient estimate in specification (6) suggests the presence of a negative and significant effect of carbon emissions on renewable energy demand. This finding implies that an increase in carbon emissions by 1 tonne per capita reduces renewable energy consumption by $0.691 \mathrm{~kg}$ of oil equivalent per capita. One plausible explanation is that declining carbon emissions may boost crop yields and consequently biomass output by alleviating the presence of greenhouse gases.

Consistent with the findings of Mahadevan and Asafu-Adjaye (2007), energy price has an adverse effect on renewable energy consumption in specifications (7) and (8). As price of renewable energy increases, renewable energy consumption reduces. This finding has an important implication for energy production subsidies in Africa. Since price is a vital determinant of renewable energy demand, policy makers should design feed-in tariffs that encourage bulk production for economies of scale and production subsidies that attract investment and reduces price for consumers.

\subsection{Robustness Checks}

Although our empirical analysis is based on the one-way random effects model, the one-way fixed effects model (Table 5.0) and of the dynamic panel data model (Table 6.0) are also estimated as a robustness check. The estimation results are reported in Table 5.0 and Table 6.0, respectively.

- Please insert Table 5.0 and Table 6.0 about here. - 
The estimation results in the one-way random effects model and the dynamic panel data model in general endorse our analysis in Section 4.1. The results suggest that real GDP per capita, and energy depletion have a positive and significant effect on renewable energy consumption. By contrast, energy price has a negative effect on renewable energy consumption. Table 6.0 also indicates that the lagged renewable energy consumption has a positive and significant effect on the actual value of renewable energy consumption.

The dynamic panel data model - estimated using the Arellano-Bond GMM estimator - allows testing for over-identification. To this end, we use the Sargan test that is distributed with a ChiSquare probability density function with $(\mathrm{p}-\mathrm{k})$ degrees of freedom, where $\mathrm{p}$ is the instrumental rank and $\mathrm{k}$ is the number of estimated coefficients in the model. The Sargan test provides the value of the J-statistic, which is then used to calculate the associated p-value. The null hypothesis that the over-identifying restrictions are valid cannot be rejected for all model specifications.

Finally we also estimate a two-way fixed effects model (results are not reported by are available from authors upon request). The results are in general supportive of the conclusions we reach in Section 4.1 .

\subsection{Conclusion and Recommendation}

Although the environmental benefits of renewable energy have been extensively studied, the potential determinants of its demand have received less attention, especially in Africa. In this paper, a one-way random effects model, a one-way fixed effects model and a dynamic panel data model are employed to estimate the effects of energy resource depletion, energy related carbon 
emissions, human capital development, capital, income and energy prices on renewable energy demand in oil producing African countries. The dynamic panel data model is estimated using the Arellano-Bond GMM estimator. The potential endogeneity issue of the explanatory variables is addressed by using an instrumental variables approach. Further, the Sargan test is employed to check for over identification.

The study finds energy resource depletion and energy-related carbon emissions as drivers of renewable energy demand. The findings also reveal that income growth has a positive impact on renewable energy consumption. Further, consistently with the related literature, energy price has an inverse relation with renewable energy demand.

The main policy recommendations arising from the study are as follows. To begin with, since income per capita increases renewable energy consumption, efforts should be made to remove technological barriers that deny consumers from accessing renewable energy. For instance, whilst the growth rate of most African countries has been encouraging over the last two decades, the volume of consumption of commercial sources of renewables outside hydro such as geothermal, solar and biofuels has not been encouraging to attract the needed investment. Policymakers should therefore create the necessary investment climate to promote the availability of commercial forms of renewables.

In addition, renewable energy policies should factor education as a medium to through which renewable energy consumption can be increased. Such educational effort should highlight the potential contribution of renewable energy to sustainable development in the face of energy resource depletion. Further, the environmental attractiveness of renewable energy should be highlighted to encourage the consumption of renewable energy. 
Finally, commercial policies such as feed-in tariffs, solar panels for individual homes and the opportunity for firms to sell excess renewable energy generated should be encouraged to promote consumption. This will enhance the choice of renewable as a substitute or complement to non-renewable energy for industries especially since power supply is intermittent in Africa.

We also suggest that, subject to availability of data, future studies should look at the determinants of non-commercial sources of renewables (charcoal, fuel wood) and the commercial sources (solar, geothermal) to promote effective renewable energy demand strategy.

\section{References}

Apergis, N. \& Payne, J. (2010). Renewable Energy Consumption And Economic Growth: Evidence from A Panel Of OECD Countries. Energy Policy, 38(1), 656-660.

Apergis, N. \& Payne, J. (2011). The Renewable Energy Consumption-Growth Nexus in Central America. Applied Energy, 88(1), 343-347.

Arellano, M., \& Bond, S. R. (1991). Some Tests of Specification for Panel Data: Monte Carlo Evidence and an Application to Employment Equations. Review of Economic Studies, 58, 277 297.

Bhattacharya, A., Das, A., \& Datta, A. (2014). Exergy Based Performance Analysis of Hydrogen Production from Rice Straw Using Oxygen Blown Gasifiation. Energy, 69, 525-533.

Boqiang, L. (2003). Economic Growth, Income Inequity, and Poverty Reduction in the China [J]. Economic Research Journal, 12, 001.

Bowden, N., \& Payne, J. E. (2010). Sectoral Analysis of the Causal Relationship between Renewable and Non-Renewable Energy Consumption and Real Output in the US. Energy Sources, Part B: Economics, Planning, and Policy, 5(4), 400-408.

Bugaje, I.M. (2006). Renewable Energy for Sustainable Development in Africa: A Review. Renewable and Sustainable Energy Reviews, 10(6), 603-612.

Chakravorty, U., Roumasset, J., \& Tse, K. (1997). Endogenous Substitution among Energy Resources and Global Warming. Journal of Political Economy, 105(6), 1201-1234.

World Energy Demand and Economic Outlook of the 2010. International Energy Outlook, www.eia.doe.gov/oiaf/ieo/world.html 
Chien, T. \& Hu, J.-L. (2008). Renewable Energy: An Efficient Mechanism to Improve GDP. Energy Policy, 36(8), 3045-3052.

Deichmann, U., Meisner, C., Murray, S., \& Wheeler, D. (2011). The Economics of Renewable Energy Expansion in Rural Sub-Saharan Africa. Energy Policy, 39(1), 215-227.

El-Ashry, Mohamed. 2009. Renewable Energy-A Global Perspective In 3rd European Renewable Energy Policy Conference. Brussels.

Fang, Y. (2011). Economic Welfare Impacts from Renewable Energy Consumption: The China Experience. Renewable and Sustainable Energy Reviews, 15(9), 5120-5128.

International Energy Association. (2010). World Energy Outlook. Paris: OECD/IEA.

International Energy Association. (2006). IEA 2006 Wind Energy Annual Report.

Isoard, S., \& Soria, A. (2001). Technical Change Dynamics: Evidence From The Emerging Renewable Energy Technologies. Energy Economics, 23(6), 619-636.

Kantai, P., 2002. 'Hot and Dirty', EcoForum Vol. 24. No. 4, Hot and Dirty: Inside Kenya's 23 billion shilling charcoal industry. Nairobi: Environment Liaison Centre International.

Karekezi, S., Kimani, J., Mutiga, A., \& Amenya, S. (2003). Energy Services for the Poor in Eastern Africa: Sub-regional "Energy Access" Study of East Africa. A report prepared for "Energy Access" Working Group of the Global Network on Energy for Sustainable Development.

Karekezi, S. (2002). Renewables in Africa - Meeting the Energy Needs of the Poor. Energy Policy, 30(11), 1059-1069.

Karekezi, S., \& Kithyoma, W. (2002). Renewable Energy Strategies for Rural Africa: Is a PVLed Renewable Energy Strategy the Right Approach for Providing Modern Energy to the Rural Poor of Sub-Saharan Africa. Energy Policy, 30(11), 1071-1086.

Karekezi, S., \& Ranja, T. (1997). Renewable energy technologies in Africa. Zed Books.

Lin, B., \& Moubarak, M. (2014). Renewable Energy Consumption - Economic Growth Nexus for China. Renewable and Sustainable Energy Reviews, 40, 111-117.

Mahadevan, R., \& Asafu-Adjaye, J. (2007). Energy Consumption, Economic Growth and Prices: A Reassessment Using Panel VECM for Developed and Developing Countries. Energy Policy, 35(4), 2481-2490.

Marques, A.C.; Fuinhas, J.A. \& Pires Manso, J.R. (2010). Motivations Driving Renewable Energy In European Countries: A Panel Data Approach. Energy Policy, 38(11), 6877-6885.

Mehrara, M. (2007). Energy Consumption and Economic Growth: The Case of Oil Exporting Countries. Energy policy, 35(5), 2939-2945.

Menyah, K. \& Wolde-Rufael, Y. (2010). CO2 Emissions, Nuclear Energy, Renewable Energy and Economic Growth. In: The US. Energy Policy, 38(6), 2911-2915.

REN21. (2009). Renewables Global Status Report Paris: REN21 Secretariate.

Sadorsky, P. (2009a). Renewable Energy Consumption, CO2 Emissions And Oil Prices In The G7 Countries. Energy Economics, 31(3), 456-462. 
Sadorsky, P. (2009b). Renewable Energy Consumption and Income in Emerging Economies. Energy Policy, 37(10), 4021-4028.

Sadorsky, P. (2011). Some Future Scenarios for Renewable Energy. Futures, 43(10), 1091-1104.

Stern, D. I., \& Cleveland, C. J. (2004). Energy and Economic Growth. Encyclopedia of energy, 2, 35-51.

Suganthi, L., \& Samuel, A. (2012). Energy Models for Demand Forecasting - A Review. Renewable and Sustainable Energy Reviews, 16, 1223-1240.

Usha Rao, K., \& Kishore, V.V.N. (2010). A Review of Technology Diffusion Models with Special Reference to Renewable Energy Technologies. Renewable and Sustainable Energy Reviews, 14, 1070-1078.

www.irena.org. (2010). Africa Renewable Future: The Path to Sustainable Development.

Wei, T. (2007). Impact of Energy Efficiency Gains on Output and Energy Use with CobbDouglas Production Function. Energy Policy, 35(4), 2023-2030.

World Energy Demand and Economic Outlook of the 2010. International Energy Outlook, www.eia.doe.gov/oiaf/ieo/world.html

World Bank. (2001). The World Bank's Energy Program: Poverty Reduction, Sustainability, and Selectivity. Energy and Mining Sector Board Paper. World Bank, Washington, DC.

http://web.worldbank.org/WBSITE/EXTERNAL/TOPICS/EXTARD/0, contentMDK:20445375 〜menuPK:1308541 pagePK:148956 piPK:216618 theSitePK:336682,00.html accessed: 17/01/20114

World Bank. (2001). World Development Report 2001/2002. World Bank, Washington, USA. 
FIGURE 1 - TIME SERIES PLOTS OF RENEWABLE ENERGY CONSUMPTION IN OIL-PRODUCING AFRICAN COUNTRIES

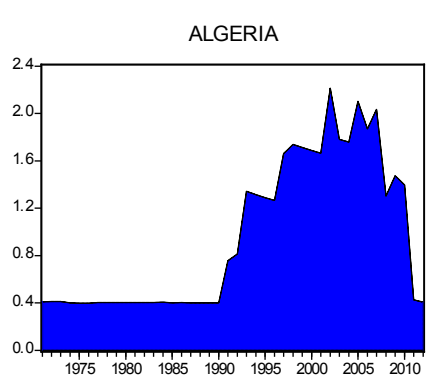

Cote_dlvoire
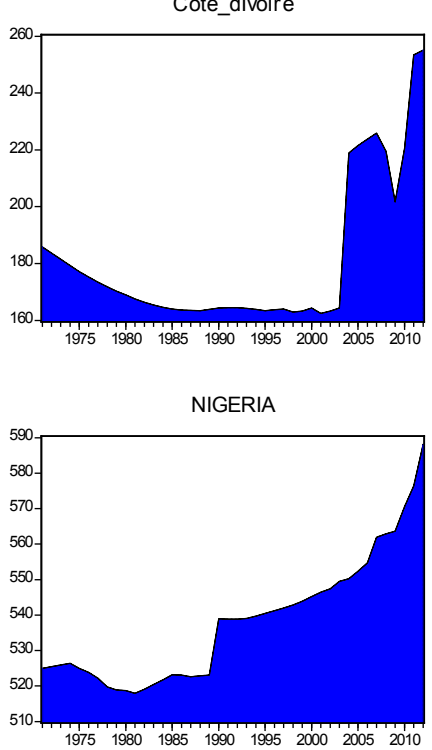

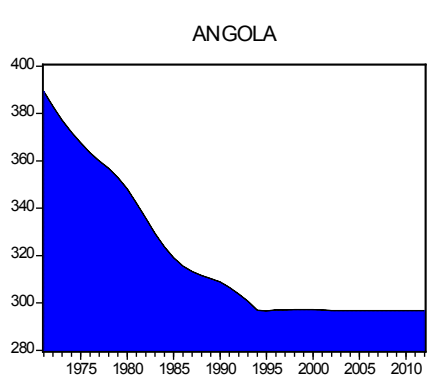

DRC

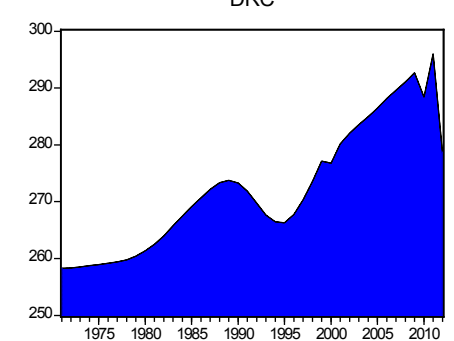

$19751980 \quad 1985 \quad 1990 \quad 1995 \quad 2000 \quad 2005 \quad 2010$

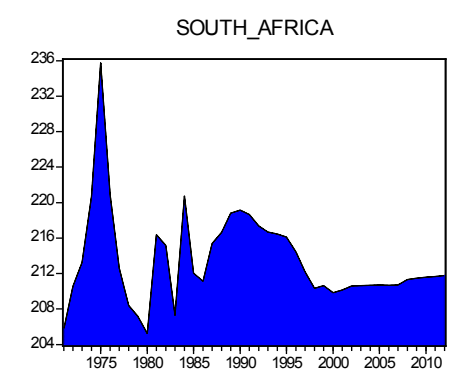

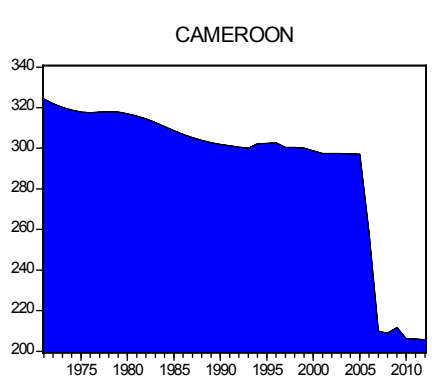

EGYPT

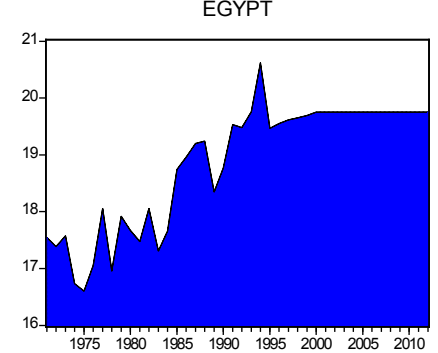

SUDAN

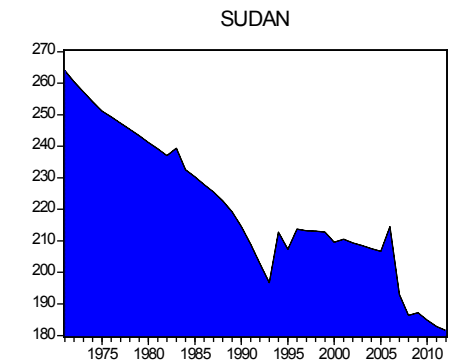

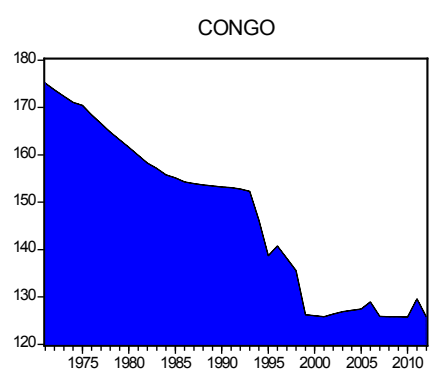

GHANA

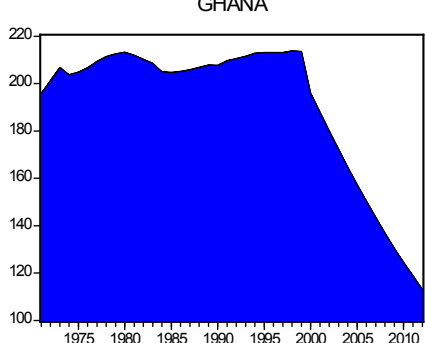

TUNISIA

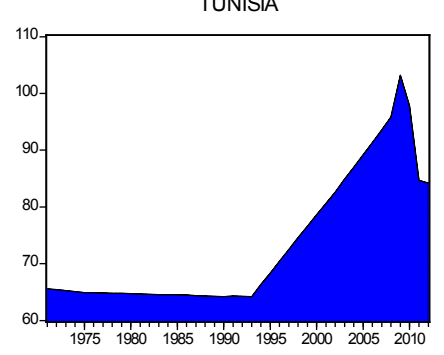

Notes: This figure depicts time series plots of renewable energy consumption of 12 oil-producing African countries. The sample period runs from 1971 to 2012 for 12 countries (Algeria, Angola, Cameroon, Congo, Democratic Republic of Congo, Côte d'Ivoire, Egypt, Gabon, Ghana, Nigeria, South Africa, Sudan and Tunisia). Renewable energy consumption is measured in $\mathrm{kg}$ of oil equivalent per capita. 


\section{TABLES}

\begin{tabular}{|c|c|c|c|c|c|c|c|c|c|c|}
\hline \multicolumn{11}{|c|}{$\begin{array}{l}\text { TABLE } 1.0 \\
\text { SUMMARY STATISTICS }\end{array}$} \\
\hline Variables & Obs & Mean & Median & Max & Min & Std & Skew & Kurt & JB & Prob \\
\hline REN & 546 & 249.8569 & 211.4062 & 822.7332 & 0.397184 & 204.9220 & 1.252984 & 4.176542 & 174.3588 & 0.0000 \\
\hline $\mathrm{Y}$ & 532 & 2275.899 & 1468.767 & 15597.28 & 103.9980 & 2234.850 & 2.278056 & 9.685465 & 1450.888 & 0.0000 \\
\hline K & 511 & 618.1821 & 326.8191 & 11463.16 & 4.339659 & 949.6882 & 5.397326 & 48.23722 & 46052.39 & 0.0000 \\
\hline $\mathrm{L}$ & 546 & 27.02791 & 17.15674 & 168.8338 & 0.600692 & 29.31108 & 2.163668 & 8.448879 & 1101.466 & 0.0000 \\
\hline $\mathrm{H}$ & 475 & 72.77842 & 45.18823 & 362.0317 & 1.131005 & 71.09408 & 1.428353 & 4.625864 & 213.8332 & 0.0000 \\
\hline $\mathrm{D}$ & 546 & 340.8256 & 87.56616 & 7214.049 & 0.000000 & 747.8989 & 4.466176 & 28.94067 & 17124.05 & 0.0000 \\
\hline $\mathrm{C}$ & 533 & 0.499111 & 0.089186 & 5.121339 & 0.001420 & 1.044864 & 2.952908 & 10.51584 & 2029.098 & 0.0000 \\
\hline $\mathrm{P}$ & 500 & 55.49849 & 45.38165 & 279.6529 & 0.000000 & 52.39420 & 0.893320 & 3.551494 & 72.83809 & 0.0000 \\
\hline
\end{tabular}

Notes: This table summarizes descriptive statistics (sample mean, median, maximum, minimum, standard deviation, skewness, kurtosis, the Jarque-Bera test statistic, and the p-value associated to the Jarque-Bera test statistic) of renewable energy consumption (REN, in kg of oil equivalent per capita), gross domestic product (Y, in real 2005 US dollars per capita), capital (K, in real 2005 US dollars per capita), labor (L, in millions of persons), human capital (H, in real 2005 US dollars per capita), energy depletion (D, in real 2005 US dollars per capita), CO2 emissions (in tonnes per capita) and the price level (consumer price index). The sample period runs from 1971 to 2012 for 12 countries (Algeria, Angola, Cameroon, Congo, Democratic Republic of Congo, Côte d'Ivoire, Egypt, Gabon, Ghana, Nigeria, South Africa, Sudan and Tunisia). Data on human capital are unavailable for Gabon. Therefore, Gabon has been excluded from the sample of country-years used to estimate our panel data models. 


\begin{tabular}{|c|c|c|c|c|c|c|c|c|}
\hline \multicolumn{9}{|c|}{$\begin{array}{l}\text { TABLE } 2.0 \\
\text { COEFFICIENTS OF CORRELATION }\end{array}$} \\
\hline Variables & REN & $\mathrm{Y}$ & K & $\mathrm{L}$ & $\mathrm{H}$ & D & $\mathrm{C}$ & $\mathrm{P}$ \\
\hline REN & 1 & & & & & & & \\
\hline Y & 0.419777 & 1 & & & & & & \\
\hline K & 0.402211 & 0.885299 & 1 & & & & & \\
\hline $\mathrm{L}$ & 0.095412 & -0.25074 & -0.23649 & 1 & & & & \\
\hline $\mathrm{H}$ & -0.41096 & 0.938114 & 0.825577 & -0.15374 & 1 & & & \\
\hline $\mathrm{D}$ & 0.551932 & 0.780035 & 0.751307 & -0.22371 & 0.221947 & 1 & & \\
\hline $\mathrm{C}$ & -0.11872 & 0.423976 & 0.201647 & 0.121383 & 0.724217 & -0.05981 & 1 & \\
\hline $\mathrm{P}$ & -0.01637 & 0.116168 & 0.014023 & 0.134497 & 0.152685 & 0.140047 & 0.085221 & 1 \\
\hline
\end{tabular}

Notes: This table summarizes the Pearson coefficients among renewable energy consumption (REN, in kg of oil equivalent per capita), gross domestic product ( $\mathrm{Y}$, in real 2005 US dollars per capita), capital (K, in real 2005 US dollars per capita), labor (L, in millions of persons), human capital (H, in real 2005 US dollars per capita), energy depletion (D, in real 2005 US dollars per capita), CO2 emissions (in tonnes per capita) and the price level (consumer price index). The sample period runs from 1971 to 2012 for 12 countries (Algeria, Angola, Cameroon, Congo, Democratic Republic of Congo, Côte d'Ivoire, Egypt, Gabon, Ghana, Nigeria, South Africa, Sudan and Tunisia). Data on human capital are unavailable for Gabon. Therefore, Gabon has been excluded from the sample of country-years used to estimate our panel data models. 


\begin{tabular}{|c|c|c|c|c|c|c|}
\hline \multicolumn{7}{|l|}{$\begin{array}{l}\text { TABLE } 3.0 \\
\text { TESTS FOF }\end{array}$} \\
\hline \multicolumn{7}{|c|}{ PANEL A - TESTS FOR PANEL INTEGRATION } \\
\hline \multirow{2}{*}{ VARIABLES } & \multicolumn{2}{|c|}{$\begin{array}{c}\text { LEVIN, LIN AND } \\
\text { CHU TEST }\end{array}$} & \multicolumn{2}{|c|}{$\begin{array}{c}\text { IM, PESARAN } \\
\text { AND SHIN TEST }\end{array}$} & \multicolumn{2}{|c|}{ PP TEST } \\
\hline & CONST & TREND & CONST & TREND & CONST & TREND \\
\hline REN & -0.2458 & 0.8319 & 2.4621 & 0.8200 & 34.1361 & 19.7403 \\
\hline Y & 2.5596 & 1.5146 & 2.3406 & 1.7419 & 17.8221 & 10.9500 \\
\hline K & 1.4384 & 1.1723 & 0.8802 & 1.1784 & 35.6284 & 26.8244 \\
\hline $\mathrm{L}$ & 4.4976 & 2.0055 & 6.2895 & 6.3868 & 1.5992 & 7.5031 \\
\hline $\mathrm{H}$ & 2.4626 & 1.8300 & 3.0459 & 2.2801 & 11.3481 & 14.2765 \\
\hline $\mathrm{D}$ & 0.7237 & 1.9536 & -2.6535 & -1.1878 & 33.7570 & 22.5577 \\
\hline $\mathrm{C}$ & -0.4633 & -2.2580 & 0.8129 & -2.2865 & 23.9542 & 19.5097 \\
\hline $\mathrm{P}$ & 8.3491 & 5.1218 & 10.3411 & 3.4161 & 0.8880 & 9.6854 \\
\hline \multicolumn{7}{|c|}{ PANEL B - KAO TEST FOR PANEL COINTEGRATION } \\
\hline & 2.2113 & & & & & \\
\hline
\end{tabular}

Notes: This table summarizes panel integration and cointegration tests of renewable energy consumption (REN, in kg of oil equivalent per capita), gross domestic product (Y, in real 2005 US dollars per capita), capital (K, in real 2005 US dollars per capita), labor (L, in millions of persons), human capital (H, in real 2005 US dollars per capita), energy depletion (D, in real 2005 US dollars per capita), CO2 emissions (in tonnes per capita) and the price level (consumer price index). The sample period runs from 1971 to 2012 for 12 countries (Algeria, Angola, Cameroon, Congo, Democratic Republic of Congo, Côte d'Ivoire, Egypt, Gabon, Ghana, Nigeria, South Africa, Sudan and Tunisia). Data on human capital are unavailable for Gabon. Therefore, Gabon has been excluded from the sample of country-years used to estimate our panel data models. Panel A summarizes results of the Levin, Lin and Chu (LLC), Im, Pesaran and Shin (IPS) and Phillips and Perron (PP) panel unit root tests. The LLC test assumes a common unit root, whereas the IPS and the PP tests assume individual unit root processes. The null hypothesis assumes the presence of a unit root in the variable. If the null is rejected then the variable is deemed to be stationary. The test statistics highlighted in bold are significant at the significance level of 5\%. Panel B summarizes the Kao test for panel cointegration. The null hypothesis of no cointegration is rejected. 


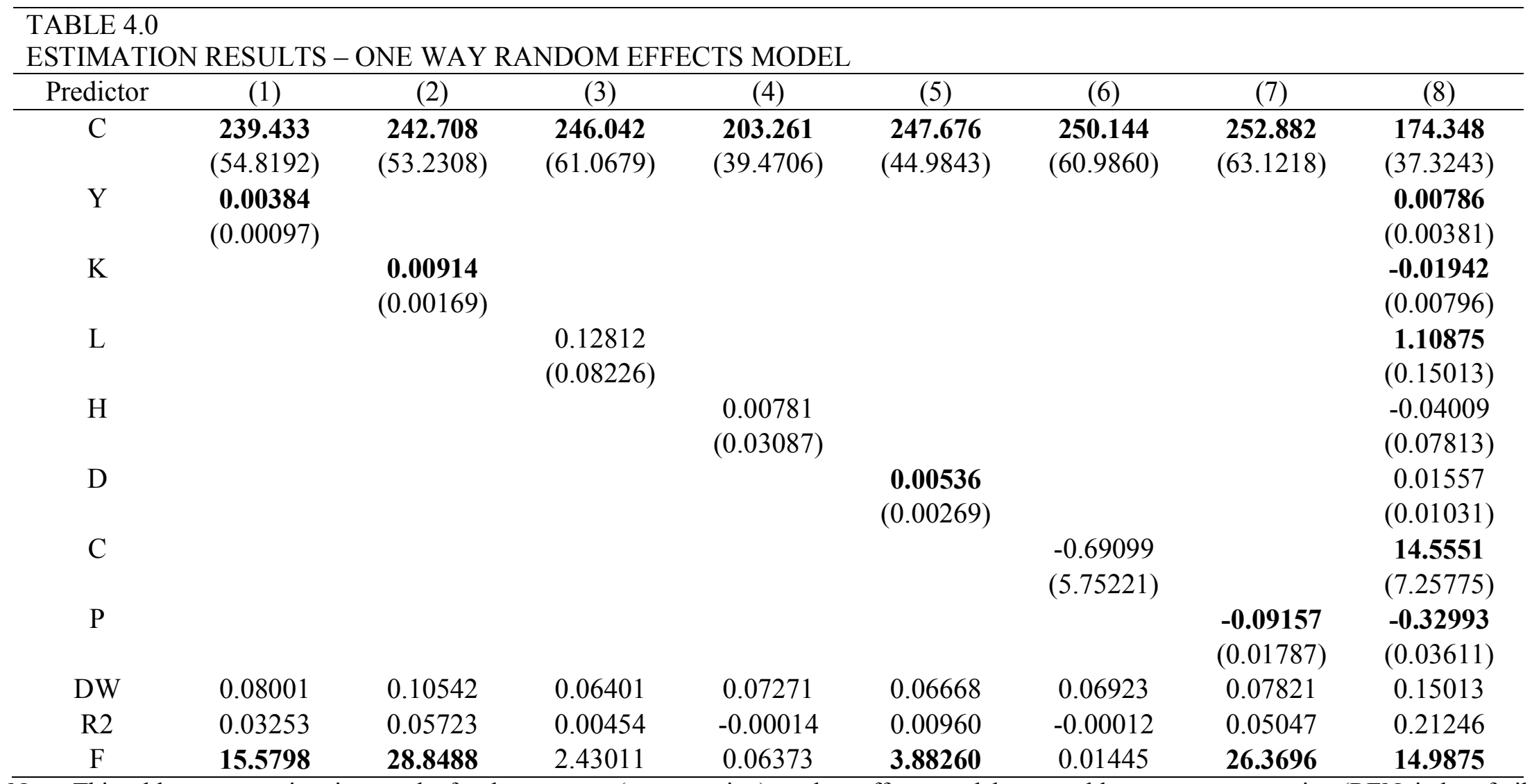

Note: This table reports estimation results for the one-way (cross section) random effects model. renewable energy consumption (REN, in kg of oil equivalent per capita), gross domestic product (Y, in real 2005 US dollars per capita), capital (K, in real 2005 US dollars per capita), population (1, in millions of persons), human capital (H, in real 2005 US dollars per capita), energy depletion (D, in real 2005 US dollars per capita), CO2 emissions ( $\mathrm{C}$, in tonnes per capita) and the price level ( $\mathrm{P}$, in index points of onsumer price index). The sample period runs from 1971 to 2012 for 12 countries (Algeria, Angola, Cameroon, Congo, Democratic Republic of Congo, Côte d'Ivoire, Egypt, Gabon, Ghana, Nigeria, South Africa, Sudan and Tunisia). Data on human capital are unavailable for Gabon. Therefore, Gabon has been excluded from the sample of country-years used to estimate our panel data models. The model has been estimated using the panel two-stage EGLS. In each equation, we use lagged predictors as instruments. Standard errors are reported in parentheses. DW is the Durbin-Watson test statistic for serial correlation of order 1 . R2 is the coefficient of determination. The F statistic (F) tests for collective significance of the explanatory variables. The coefficient estimates highlighted in bold are significant at the significance level of $5 \%$. 


\begin{tabular}{|c|c|c|c|c|c|c|c|c|}
\hline \multicolumn{9}{|c|}{$\begin{array}{l}\text { TABLE } 5.0 \\
\text { ESTIMATION RESULTS - ONE WAY FIXED EFFECTS MODEL }\end{array}$} \\
\hline Predictor & (1) & (2) & (3) & (4) & (5) & (6) & (7) & (8) \\
\hline $\mathrm{C}$ & $\begin{array}{l}\mathbf{2 3 8 . 0 7 1 5} \\
(2.39004)\end{array}$ & $\begin{array}{l}\mathbf{2 3 5 . 1 9 1 6} \\
(1.36917)\end{array}$ & $\begin{array}{l}\mathbf{2 4 6 . 0 6 4 6} \\
(2.42983)\end{array}$ & $\begin{array}{l}\mathbf{1 9 9 . 9 1 7 9} \\
(2.43611)\end{array}$ & $\begin{array}{l}\mathbf{2 4 0 . 7 5 4 5} \\
(1.31403)\end{array}$ & $\begin{array}{l}\mathbf{2 5 0 . 0 4 7 8} \\
(3.04675)\end{array}$ & $\begin{array}{l}\mathbf{2 5 8 . 6 1 3 9} \\
(1.35578)\end{array}$ & $\begin{array}{l}\mathbf{1 6 6 . 1 5 5 3} \\
(4.84686)\end{array}$ \\
\hline $\mathrm{Y}$ & $\begin{array}{c}\mathbf{0 . 0 0 3 7 9} \\
(0.00097)\end{array}$ & & & & & & & $\begin{array}{r}\mathbf{0 . 0 0 7 9 4} \\
(0.00383)\end{array}$ \\
\hline K & & $\begin{array}{c}\mathbf{0 . 0 0 9 0 9} \\
(0.00170)\end{array}$ & & & & & & $\begin{array}{l}-\mathbf{0 . 0 1 9 0 1} \\
(0.00800)\end{array}$ \\
\hline $\mathrm{L}$ & & & $\begin{array}{c}0.12727 \\
(0.08231)\end{array}$ & & & & & $\begin{array}{r}\mathbf{1 . 0 8 9 4 7} \\
(0.15178)\end{array}$ \\
\hline $\mathrm{H}$ & & & & $\begin{array}{c}0.01003 \\
(0.03093)\end{array}$ & & & & $\begin{array}{l}-0.04207 \\
(0.07855)\end{array}$ \\
\hline D & & & & & $\begin{array}{c}\mathbf{0 . 0 0 5 1 3} \\
(0.00270)\end{array}$ & & & $\begin{array}{r}\mathbf{0 . 0 1 5 0 4} \\
(0.01037)\end{array}$ \\
\hline $\mathrm{C}$ & & & & & & $\begin{array}{l}-0.49985 \\
(5.78073)\end{array}$ & & $\begin{array}{r}15.9011 \\
(7.44040)\end{array}$ \\
\hline $\mathrm{P}$ & & & & & & & $\begin{array}{c}\mathbf{- 0 . 0 9 1 5 6} \\
(0.01787)\end{array}$ & $\begin{array}{r}-\mathbf{0 . 3 2 8 4 6} \\
(0.03645)\end{array}$ \\
\hline DW & 0.08200 & 0.10817 & 0.06538 & 0.07473 & 0.06889 & 0.07072 & 0.07993 & 0.15426 \\
\hline $\mathrm{R} 2$ & 0.99101 & 0.99146 & 0.98948 & 0.98117 & 0.98926 & 0.99033 & 0.99137 & 0.98692 \\
\hline $\mathrm{F}$ & 4267.65 & 4304.38 & 3753.34 & 2007.70 & 3762.22 & 3985.03 & 4176.00 & 1587.27 \\
\hline
\end{tabular}

Note: This table reports estimation results for the one-way fixed effects model. renewable energy consumption (REN, in kg of oil equivalent per capita), gross domestic product (Y, in real 2005 US dollars per capita), capital (K, in real 2005 US dollars per capita), population (l, in millions of persons), human capital (H, in real 2005 US dollars per capita), energy depletion (D, in real 2005 US dollars per capita), CO2 emissions (in tonnes per capita) and the price level (consumer price index). The sample period runs from 1971 to 2012 for 12 countries (Algeria, Angola, Cameroon, Congo, Democratic Republic of Congo, Côte d'Ivoire, Egypt, Gabon, Ghana, Nigeria, South Africa, Sudan and Tunisia). Data on human capital are unavailable for Gabon. Therefore, Gabon has been excluded from the sample of country-years used to estimate our panel data models. The model has been estimated using the panel two-stage least squares estimation procedure. In each equation, we use lagged predictors as instruments. Standard errors are reported in parentheses. DW is the Durbin-Watson test statistic for serial correlation of order 1 . R2 is the coefficient of determination adjusted by the degrees of freedom. The F statistic (F) tests for collective significance of the explanatory variables. The coefficient estimates highlighted in bold are significant at the significance level of $5 \%$. 


\begin{tabular}{|c|c|c|c|c|c|c|c|c|}
\hline $\begin{array}{l}\text { TABLE } 6 \\
\text { ESTIMA }\end{array}$ & ESULTS & NAMIC PA & EL DATA & DEL & & & & \\
\hline Predictor & (1) & (2) & (3) & (4) & (5) & (6) & (7) & (8) \\
\hline $\mathrm{C}$ & $\begin{array}{l}\mathbf{2 3 5 . 3 4 7 9} \\
(5.81107)\end{array}$ & $\begin{array}{l}\mathbf{2 3 5 . 6 6 9 1} \\
(1.27381)\end{array}$ & $\begin{array}{l}\mathbf{2 2 0 . 0 5 1 0} \\
(7.80277)\end{array}$ & $\begin{array}{l}\mathbf{2 0 0 . 4 7 8 3} \\
(9.54857)\end{array}$ & $\begin{array}{l}\mathbf{2 4 7 . 0 7 8 7} \\
(1.89704)\end{array}$ & $\begin{array}{l}\mathbf{2 3 4 . 0 0 4 8} \\
(9.24581)\end{array}$ & $\begin{array}{r}\mathbf{2 5 5 . 8 8 4 3} \\
(11.0985)\end{array}$ & $\begin{array}{l}-1.80022 \\
(2.70475)\end{array}$ \\
\hline $\mathrm{Y}$ & $\begin{array}{c}\mathbf{0 . 0 0 4 9 8} \\
(0.00253)\end{array}$ & & & & & & & $\begin{array}{c}0.00118 \\
(0.00125)\end{array}$ \\
\hline K & & $\begin{array}{c}\mathbf{0 . 0 0 8 3 2} \\
(0.00205)\end{array}$ & & & & & & $\begin{array}{l}\mathbf{- 0 . 0 0 3 8 4} \\
(0.00173)\end{array}$ \\
\hline $\mathrm{L}$ & & & $\begin{array}{c}\mathbf{1 . 0 7 9 6 1} \\
(0.28565)\end{array}$ & & & & & $\begin{array}{c}\mathbf{0 . 0 7 3 1 5} \\
(0.04417)\end{array}$ \\
\hline $\mathrm{H}$ & & & & $\begin{array}{c}0.00235 \\
(0.13077)\end{array}$ & & & & $\begin{array}{c}-0.02524 \\
(0.02184)\end{array}$ \\
\hline D & & & & & $\begin{array}{c}0.00707 \\
(0.00545)\end{array}$ & & & $\begin{array}{c}\mathbf{0 . 0 0 5 7 8} \\
(0.00204)\end{array}$ \\
\hline $\mathrm{C}$ & & & & & & $\begin{array}{c}31.3417 \\
(18.3508)\end{array}$ & & $\begin{array}{c}1.57330 \\
(2.68618)\end{array}$ \\
\hline $\mathrm{P}$ & & & & & & & $\begin{array}{c}-0.04339 \\
(0.19585)\end{array}$ & $\begin{array}{c}-0.03277 \\
(0.02461)\end{array}$ \\
\hline REN(-1) & & & & & & & & $\begin{array}{c}\mathbf{1 . 0 0 3 0 7} \\
(0.01527)\end{array}$ \\
\hline DW & 0.08740 & 0.10567 & 0.08213 & 0.07228 & 0.07534 & 0.08668 & 0.07648 & 1.52504 \\
\hline $\mathrm{R} 2$ & 0.99172 & 0.99213 & 0.99235 & 0.98242 & 0.99072 & 0.99190 & 0.99154 & 0.99872 \\
\hline
\end{tabular}

Note: This table reports estimation results for the dynamic panel data model, estimated using the Arellano-Bond GMM estimation method. The dependent variable in this model is renewable energy consumption (REN, in $\mathrm{kg}$ of oil equivalent per capita). The explanatory variables are gross domestic product (Y, in real 2005 US dollars per capita), capital (K, in real 2005 US dollars per capita), population (L, in millions of persons), human capital (H, in real 2005 US dollars per capita), energy depletion (D, in real 2005 US dollars per capita), CO2 emissions (in tonnes per capita) and the price level (consumer price index). The sample period runs from 1971 to 2012 for 12 countries (Algeria, Angola, Cameroon, Congo, Democratic Republic of Congo, Côte d'Ivoire, Egypt, Gabon, Ghana, Nigeria, South Africa, Sudan and Tunisia). Data on human capital are unavailable for Gabon. Therefore, Gabon has been excluded from the sample of country-years used to estimate our panel data models. Standard errors are reported in parentheses. DW is the Durbin-Watson test statistic for serial correlation of order 1 . R2 is the coefficient of determination. The coefficient estimates highlighted in bold are significant at the significance level of 5\%. 